\title{
Extração e análise eletroforética em gel de poliacrilamida (SDS-PAGE) de proteínas totais de folhas e raízes de Piper tuberculatum
}

\author{
Redinaldo dos Santos SILVA ${ }^{1,2}$, Cláudia Regina Batista de SOUZA ${ }^{1,3}$ \\ RESUMO \\ O Estado do Pará é o principal produtor brasileiro de pimenta-do-reino (Piper nigrum Link), entretanto a sua produção tem \\ sido bastante afetada pela doença conhecida como fusariose. O Fusarium solani f. sp. piperis é o agente causador desta doença \\ que afeta o sistema radicular da planta, causando o apodrecimento das raízes e a queda das folhas levando à morte da planta. \\ Algumas piperáceas nativas da região amazônica, entre elas a espécie Piper tuberculatum Jacq., têm se mostrado resistentes à \\ infecção pelo $F$ solani f. sp. piperis, e desta forma têm sido utilizadas em estudos de interação planta-patógeno. Neste trabalho \\ foram avaliadas cinco condições de extração de proteínas com o objetivo de selecionar tampões adequados para a extração \\ de proteínas totais de folhas e raízes de $P$. tuberculatum. Os tampões utilizados para a extração de proteínas de raízes e folhas \\ foram: tampão salino, tampão sacarose, tampão glicerol, tampão uréia e tampão fosfato de sódio. As análises quantitativas \\ mostraram que os tampōes sacarose, glicerol e uréia foram mais eficientes na extração de proteínas de folhas e raízes. Análises \\ de SDS-PAGE mostraram padrōes diferenciados de bandas em extratos protéicos de folhas e raízes obtidos com os diferentes \\ tampões. Os resultados obtidos neste trabalho contribuem para a identificação de tampões de extração adequados para a \\ obtenção de amostras de proteínas totais em estudos de interação $P$. tuberculatum - F. solani f. sp. piperis.
}

PalaVRaS-Chave: Fusariose, Fusarium solani f. sp. piperis, Piper nigrum, Piper tuberculatum, Proteômica, SDS-PAGE.

\section{Extraction and polyacrylamide gels electrophoresis analysis (SDS-PAGE) of total protein from leaves and roots of Piper tuberculatum}

\begin{abstract}
The Pará State is the principal Brazilian producer of black pepper (Piper nigrum Link), however, the spice's production has been damaged by the Fusarium disease. The Fusarium solani f. sp. piperis, causal agent of this disease which attacks the plant root system promoting the root rot, leaves fall and plant death. Piperaceae plants endemic of Amazon region and resistant to $F$. solani f. sp. piperis infection, such as Piper tuberculatum Jacq., which has been studied in order to understand this host-pathogen interaction. In this work were evaluated five conditions for total protein extraction aiming to select suitable buffers for extraction of total proteins from $P$. tuberculatum leaves and roots. The conditions used to roots and leaves protein extractions were salt buffer, sucrose buffer, glycerol buffer, urea buffer and sodium phosphate buffer. Quantitative analysis showed that sucrose, glycerol and urea buffers were more efficient for leaves and roots protein extractions. SDS-PAGE analysis showed distinct band patterns in leaves and roots protein extracts obtained with different buffers. Our results could support the selection of extraction buffers for proteomics analysis in $P$. tuberculatum - F. solani $\mathrm{f}$ sp. piperis interaction studies.
\end{abstract}

KEY WORDS: Fusarium disease, Fusarium solani f. sp. piperis, Piper nigrum, Piper tuberculatum, Proteomics, SDS-PAGE.

\footnotetext{
1 Universidade Federal do Pará, Laboratório de Biologia Molecular, Rua Augusto Correa 01, Guamá-Belém -PA, Brasil. Fone: 32017558.

2 Bolsista PIBIC-UFPA.

${ }^{3}$ E-mail: bsouza@ufpa.br
} 


\section{INTRODUÇÃO}

O gênero Piper é o maior da família Piperaceae e inclui a pimenteira-do-reino (Piper nigrum Link), planta trepadeira que cresce aderida a tutores de madeira ou troncos de árvores, produzindo frutos do tipo baga amplamente comercializados como condimentos alimentares. Sua cultura é milenar tendo a exploração e o comércio iniciados na Índia, de onde se espalhou para Oriente Médio e a Europa.

A introdução da pimenteira-do-reino no Brasil ocorreu no século XVII, no Estado da Bahia, sendo levada em seguida para os Estados da Paraíba, Maranhão e Pará. Todavia, a exploração econômica foi estabelecida a partir de 1933, com a introdução do cultivar kuching, registrada no Brasil como Cingapura-BRA-019, por imigrantes japoneses que se fixaram no município de Tomé-Açú, Estado do Pará. A adaptação da pimenteira foi tão satisfatória que houve um aumento da produtividade e geração de bons lucros para os agricultores, fazendo com que o Brasil passasse de importador a um dos grandes exportadores mundiais. No entanto, a partir de 1957 esta cultura começou a ser afetada por uma doença que ataca o sistema radicular, conhecida como podridão das raízes ou fusariose. Esta enfermidade, causada pelo fungo Fusarium solani $\mathrm{f}$. sp. piperis tem causado a morte de milhares de pimenteiras, resultando em grandes perdas de produção e redução do ciclo produtivo da cultura. Entre os sintomas da doença destacam-se a perda progressiva de folhas e internódios e o apodrecimento das raízes que leva à morte da planta (Duarte et al., 2002).

Uma das estratégias utilizadas para tentar controlar a doença foi à busca por materiais resistentes, contudo devido à estreita base genética do material disponível no Brasil e ao fato do patógeno não existir no país de origem da espécie (Poltronieri et al., 2000), é muito pouco provável a existência de plantas de pimenteira-do-reino resistentes à fusariose. Neste contexto, pesquisadores da Embrapa Amazônia Oriental (Belém-PA) testaram piperáceas da Amazônia e identificaram algumas espécies com resistência a infecção pelo patógeno, entre elas a Piper tuberculatum Jacq. (Albuquerque et al., 2001), contudo os processos celulares e moleculares envolvidos neste mecanismo de resistência ainda são desconhecidos.

Os mecanismos de resistência de plantas a patógenos são bastante estudados em diversas espécies. Relatos mostram que durante uma infecção por um patógeno, a planta produz moléculas como ácido jasmônico, ácido salićlico e etileno (Kumar \& Klessig, 2000) que participam de uma complexa rede de sinais que culmina com a expressão de genes relacionados à defesa (Medeiros et al., 2003; Nürnberger, 1999). A Resistência Sistêmica Adquirida (SAR) é um mecanismo bastante complexo durante o qual há a ativação de genes do tipo PR (relacionados à patogênese) que codificam proteínas com comprovada atividade anti-microbiana (Osbourn, 1996; Dangl et al., 2001; Medeiros et al., 2003).

Nos últimos anos tem sido cada vez mais crescente a identificação de genes e proteínas relacionados ao mecanismo de resistência a patógenos e sua utilização na obtenção de plantas geneticamente modificadas. Para identificar essas moléculas, várias metodologias modernas podem ser empregadas, como é o caso da proteômica, que vem sendo utilizada com sucesso em estudos de interação planta-patógeno em diferentes culturas de importância sócio-econômica (Peck et al., 2001; Kim et al., 2003; Colditz et al., 2004; Castillejo et al., 2004; Wang et al., 2006; Sharma et al., 2007). Desta forma, a proteômica representa uma poderosa ferramenta para a identificação de proteínas relacionadas ao mecanismo de resistência de $P$. tuberculatum ao patógeno $F$. solani $\mathrm{f}$. sp. piperis.

Em estudos de proteômica, uma boa preparação da amostra, ou seja, a extração do máximo número de proteínas de uma dada célula, tecido, órgão ou organismo, é o mais importante passo para a subseqüente separação, resolução e identificação das proteínas (Park, 2004). Sendo assim, a primeira etapa a ser realizada em estudos de proteômica, consiste na padronização do processo de extração protéica para o tipo de tecido estudado, com o objetivo de se ter um bom rendimento em termos quantitativos, além de uma maior variabilidade de bandas, de forma a maximizar o número de proteínas presentes na amostra a ser avaliada.

Neste contexto, considerando-se a necessidade de amostras protéicas adequadas para estudos de proteômica da interação P. tuberculatum - F. solani f. sp. piperis, o presente trabalho teve como objetivo testar diferentes protocolos para a extração de proteínas totais de folhas e raízes desta espécie e avaliar os extratos obtidos através de análise eletroforética em gel de poliacrilamida (SDS-PAGE).

\section{MATERIAIS E MÉTODOS}

\section{MATERIAL VEGETAL}

Plantas de P. tuberculatum com 30 dias de desenvolvimento foram gentilmente cedidas por Ilmarina Campos de Menezes, da EMBRAPA Amazônia Oriental (Belém-PA).

\section{EXTRAÇÃO DE PROTEÍNAS TOTAIS E QUANTIFICAÇÃO}

Amostras contendo cerca de $500 \mathrm{mg}$ de tecidos de folhas e raízes foram maceradas na presença de nitrogênio líquido e extraídas com $1 \mathrm{~mL}$ de diferentes tampões de extração: tampão salino [50 mM Tris, $500 \mathrm{mM} \mathrm{NaCl}, 50 \mathrm{mM}$ EDTA, $5 \mathrm{mM}$ $\mathrm{MgCl}_{2}, 2$ mM PMSF, pH 7.5], tampão fosfato de sódio [50 $\mathrm{mM} \mathrm{Na}_{2} \mathrm{HPO}_{4}, 30 \mathrm{mM} \mathrm{NaCl}, 10 \mathrm{mM}$ DTT, $2 \mathrm{mM}$ PMSF, $\mathrm{pH}$ 7.2], tampão sacarose [700 $\mathrm{mM}$ sacarose, $500 \mathrm{mM}$ Tris, 
50 mM EDTA, 100 mM KCl, 2 mM PMSF, pH 8.0 (De Mot \& Vanderleyden, 1989)], tampão glicerol [50 mM Tris-HCl, 5\% glicerol, $100 \mathrm{mM} \mathrm{KCl,} 100 \mathrm{mM}$ DTT, 4\% Triton, 2 mM PMSF, pH 8.0 ] e tampão uréia [5 M uréia, $4 \%$ Triton, $100 \mathrm{mM}$ DTT, $\left.50 \mathrm{mM} \mathrm{Na} \mathrm{PO}_{4}, \mathrm{pH}: 7.0\right]$. O material foi centrifugado a $14.000 \mathrm{xg}$ por $30 \mathrm{~min}$ a $4^{\circ} \mathrm{C}$ e o sobrenadante foi coletado e armazenado a $-20^{\circ} \mathrm{C}$.

A concentração dos extratos protéicos foi determinada utilizando-se o fluorímetro Qubit, da Invitrogen, seguindo as orientações do fornecedor.

\section{ELETROFORESE EM GEL DE POLIACRILAMIDA (SDS-PAGE)}

Amostras contendo quantidades conhecidas de proteínas foram adicionadas a igual volume de tampão de amostra (glicerol $10 \%, \beta$-mercaptoetanol 5\%, SDS 2,3\%, Tris- $\mathrm{HCl}$ $\mathrm{pH}$ 6,8 0,0625 M), fervidas por três minutos, centrifugadas rapidamente e aplicadas no gel. Os géis de 12\% de SDSpoliacrilamida (Laemmli, 1970) com $1 \mathrm{~mm}$ de espessura foram confeccionados e submetidos a uma corrente de 30 $\mathrm{mA}$, com voltagem constante em um sistema de mini-gel, Hoefer miniVE-Vertical electrophoresis System, da Amersham Pharmacia Biotech. Após a corrida, os géis foram corados com Coomassie Brilliant Blue e nitrato de prata de acordo com protocolos descritos na literatura (Oakley et al., 1980) e posteriormente escaneados utilizando o scanner One touch, da Visioneer.

\section{RESULTADOS E DISCUSSÃO}

Na Tabela 1 constam os dados de quantificação fluorimétrica dos extratos protéicos totais de folhas e raízes de plantas de $P$. tuberculatum obtidos utilizando-se cinco diferentes tampões de extração descritos na literatura.

A comparação dos métodos de extração revelou valores de rendimento bastante distintos. De acordo com os resultados obtidos, os tampões sacarose, glicerol e uréia foram os que proporcionaram maior rendimento na extração de proteínas totais de raízes quanto de folhas, quando comparados com os demais tampóes. Nos extratos de folhas obtidos com esses tampões foram observados valores que variaram de 2200 a $3244 \mu \mathrm{g} / \mathrm{mL}$, enquanto para os tampóes fosfato e salino, os valores apresentados foram 386 e $896 \mu \mathrm{g} / \mathrm{mL}$, respectivamente. Um rendimento menor foi observado também em extratos de raízes obtidos com os tampóes fosfato e salino (332 e 460 ug/ $\mathrm{mL}$, respectivamente), enquanto para os tampóes sacarose, glicerol e uréia os valores variaram de 814 a $1512 \mu \mathrm{g} / \mathrm{mL}$.

Desta forma, podemos concluir que em termos quantitativos os tampões sacarose, glicerol e uréia foram mais eficientes tanto para a extração de proteínas totais de raízes quanto de folhas, visto que apresentaram maior rendimento.
Tabela 1: Dados de quantificação fluorimétrica de extratos protéicos totais de folhas e raízes de $P$. tuberculatum. Amostras contendo $500 \mathrm{mg}$ de tecidos foram extraídas com $1 \mathrm{~mL}$ de diferentes tipos de tampões.

\begin{tabular}{ll}
\hline Extrato protéico & $\begin{array}{l}\text { Concentração protéica } \\
(\mu \mathrm{g} / \mathrm{mL})\end{array}$ \\
\hline Folhas em tampão salino & 896 \\
\hline Folhas em tampão fosfato & 386 \\
\hline Folhas em tampão sacarose & 2200 \\
\hline Folhas em tampão glicerol & 3256 \\
\hline Folhas em tampão uréia & 3244 \\
\hline Raízes em tampão salino & 460 \\
\hline Raízes em tampão fosfato & 332 \\
\hline Raízes em tampão sacarose & 1192 \\
\hline Raízes em tampão glicerol & 814 \\
\hline Raízes em tampão uréia & 1512 \\
\hline
\end{tabular}

A capacidade desses tampóes em extrair mais eficientemente as proteínas de folhas e raízes está relacionada com propriedades da uréia, detergente triton e sacarose em favorecer a ruptura de membranas celulares e a solubilização de diferentes classes de proteínas (Chinnasamy \& Rampitsch, 2006; Vâlcu \& Schlink, 2006; Weiss \& Görg, 2008).

As análises em SDS-PAGE (Figura 1) mostraram que os extratos protéicos de folhas obtidos com os diferentes tampões apresentaram bandas que variaram de 10 a $220 \mathrm{kDa}$. Comparando-se os padróes das bandas, pode-se observar que as amostras obtidas com os tampões fosfato e sacarose apresentaram um maior número de bandas.

$\mathrm{Na}$ maioria das amostras foram observadas duas bandas mais abundantes correspondentes à enzima Ribulose bi-fosfato carboxilase (Rubisco), que quando analisada em condiçōes desnaturantes (SDS-PAGE) é visualizada na forma de

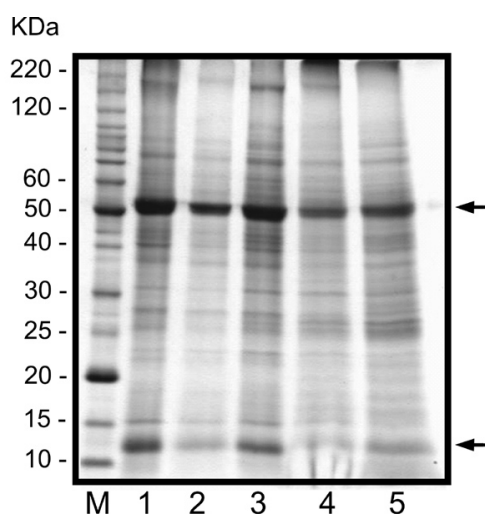

Figura 1 - Análise eletroforética de extratos protéicos de folhas de $P$. tuberculatum Jacq em gel de poliacrilamida corado com Coomassie Brilliant Blue. M- Marcador molecular (KDa), 1 - Extrato protéico obtido com tampão fosfato de sódio; 2 - Extrato protéico obtido com tampão salino; 3 - Extrato protéico obtido com tampão sacarose; 4 - Extrato protéico obtido com tampão glicerol; 5 - Extrato protéico obtido com tampão uréia. As setas indicam as subunidades da enzima Rubisco. 
subunidades maior e menor, como peso molecular de $52 \mathrm{kDa}$ e $13 \mathrm{kDa}$, respectivamente (Desimone et al.,1996; Peng-Da MA et al. 2004). É claramente evidenciado na Figura 1, que nas amostras obtidas com os tampóes fosfato e sacarose, além de um maior número de bandas, as bandas correspondentes às subunidades da Rubisco estão mais intensas que nas demais amostras, comprovando uma maior eficiência destes dois tampóes quanto à capacidade de extração. Contudo, de acordo com a análise quantitativa por fluorimetria, o tampão fosfato foi o que apresentou menor rendimento (Tabela 1). Sendo assim, podemos concluir que dentre os tampões testados, o tampão sacarose foi mais eficiente para extração de folhas, visto que produziu amostra com maior número de bandas e um bom rendimento $(2200 \mu \mathrm{g} / \mathrm{mL})$.

$\mathrm{Na}$ Figura 2A são mostrados os padrões de extratos protéicos de raízes analisados em gel de poliacrilamida corado com Coomassie Brilliant Blue. Os extratos obtidos com diferentes tampões apresentaram bandas que variaram de 15 a $120 \mathrm{kDa}$. De acordo com a análise em SDS-PAGE, as amostras extraídas com os tampões salino e sacarose apresentaram padrões de bandas similares entre si, contudo se pode observar um grupo de proteínas com peso molecular variando de 30 a $40 \mathrm{kDa}$ com maior intensidade na amostra com tampão sacarose (Figura 2A, poço 3). Por outro lado, foram observados padrōes de bandas similares entre as amostras extraídas com os tampóes fosfato e glicerol, enquanto bandas com tamanhos que variam de 50 a $120 \mathrm{kDa}$ foram visualizadas preferencialmente na amostra obtida com tampão uréia (Figura $2 \mathrm{~A}$, poço 4 ).

Quando os métodos de coloração foram comparados, pôde-se verificar que algumas bandas ficaram bem mais evidentes na Figura 2B, como é o caso do grupo de proteína de 30 a $40 \mathrm{kDa}$ da amostra obtida a partir de extração com tampão salino. Esta diferença entre os métodos de coloração era esperada devido à maior sensibilidade da coloração com nitrato de prata que é capaz de detectar de 0.1 a $1.0 \mathrm{ng}$ de proteína, enquanto a sensibilidade do Coomassie Brilliant Blue é de 100 ng de proteínas (Patton, 2002).

Considerando-se os dados das análises quantitativa e qualitativa obtidos no presente trabalho, pode-se concluir que para a extração de proteínas totais de raízes, os tampões sacarose e uréia são os mais indicados, pois produziram amostras com maior rendimento $(1192 \mu \mathrm{g} / \mathrm{mL}$ e $1512 \mu \mathrm{g} /$ $\mathrm{mL}$, respectivamente) e maior número de bandas que os demais tampões. Como foram observadas bandas diferenciais em amostras extraídas com cada um desses dois tampões, é sugerido que nas análises em géis bidimensionais sejam utilizadas amostras extraídas com esses dois tipos de tampóes, para se obter um maior número de proteínas.

Estudos em proteômica têm sido reportados em culturas economicamente importantes, como algodão, café e soja
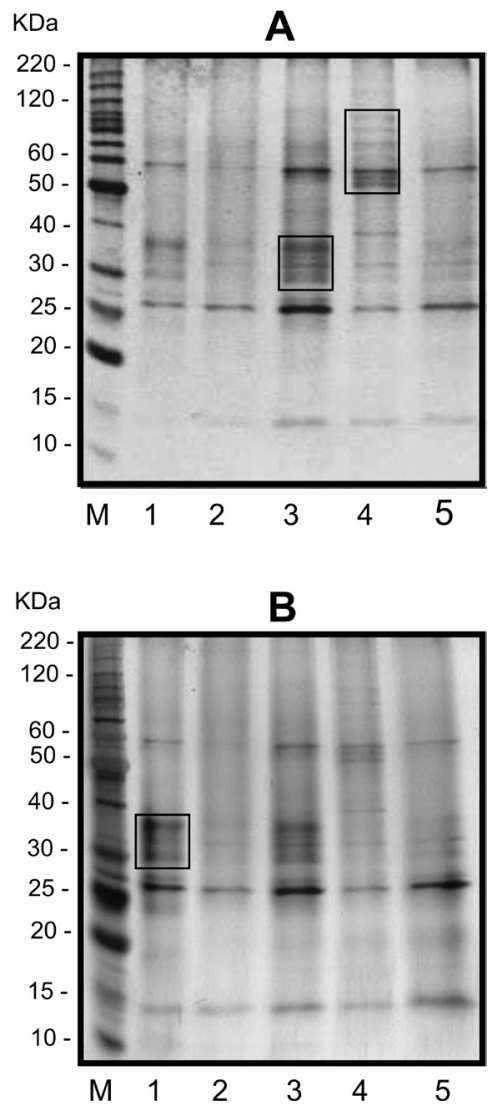

Figura 2 - Análise eletroforética (SDS-PAGE) de extratos protéicos $(3 \mu \mathrm{g})$ de raízes de $P$. tuberculatum Jacq. Em $A$, coloração com azul de Coomassie, em $\mathrm{B}$, coloração com nitrato de prata. M- Marcador molecular (KDa), 1 - Extrato protéico obtido com tampão salino; 2 - Extrato protéico obtido com tampão fosfato de sódio; 3 - Extrato protéico obtido com tampão sacarose; 4 - Extrato protéico obtido com tampão uréia; 5 - Extrato protéico obtido com tampão glicerol. As caixas na Figura A indicam as bandas diferenciais observadas nas amostras obtidas com os tampões sacarose e uréia. A caixa na Figura B indica as bandas que ficaram mais evidentes com a coloração com prata.

(Galau et al., 1991; Yamamoto \& Knap, 2001; Morgano et al., 2005), entretanto, a expressão de proteínas em raízes tem sido pouco estudada, havendo, portanto, poucos relatos de padronização de protocolos para extração de proteínas de raízes disponíveis na literatura. De acordo com relato de Caetano et al. (2007), o tampão sacarose (De Mot \& Vanderleyden, 1989) também se mostrou eficiente na extração de proteínas de raízes de feijão-corda infectadas com Meloidogyne incognita, visto que amostra obtida a partir deste tampão, avaliada por eletroforese bi-dimensional, apresentou 250 proteínas, em comparação com a amostra obtida a partir do tampão relatado por Xie et al. (2007) que apresentou 200 proteínas. Os dados gerados no presente trabalho não nos permitem estimar os números de proteínas obtidas com os diferentes tampões, visto que as análises ficaram restritas a géis uni-dimensionais, contudo, 
etapas futuras incluirão a obtenção de extratos protéicos de raízes de plantas infectadas e a subseqüente análise em géis bi-dimensionais e/ou espectometria de massa.

O presente trabalho é pioneiro na análise de padrões protéicos de P. tuberculatum e contribui para a identificação de tampões de extração adequados para a obtenção de amostras de proteínas totais em estudos de interação desta espécie com o patógeno $F$ solani f. sp. piperis.

\section{AGRADECIMENTOS}

Os autores agradecem à UFPA e ao CNPq pela concessão das bolsas de Iniciação Cientifica e Iniciação Tecnológica, respectivamente, a Redinaldo dos Santos Silva. Ao CNPq e SECTAM-FUNTEC-PA/FAPESPA pelo apoio financeiro ao projeto "Estudos moleculares do mecanismo de resistência à fusariose em plantas de pimenta nativas da região amazônica". À Doutoranda Ilmarina Campos de Menezes por ter cedido o material vegetal. À Dra. Alessandra de Rezende Ramos pelos primeiros ensinamentos na análise de proteínas dados ao aluno Redinaldo Silva.

\section{BIBLIOGRAFIA CITADA}

Albuquerque, F.C. de; Duarte, M.L.R.; Benchimol, R.L.; Endo, T. 2001. Resistência de piperaceas nativas da Amazônia à infecção causada por Nectria haematococca f. sp. piperis. Acta Amazonica, v.31, n.3, p.341-348.

Caetano, P.; Santana, C.G.; Carneiro, R.M.D.; Grossi de Sá, M.F.; Oliveira, J.T.A.; Mehta, A. 2007. Otimização de protocolos para extração de proteínas em raízes de feijāo-de-corda (Vigna unguiculata) infectadas com o nematóide Meloidogyne incognita. Boletim de Pesquisa e Desenvolvimento/Embrapa Recursos Genéticos e Biotecnologia, ISSN 1676-1340; 210.

Castillejo, M.A.; Amiour, N.; Dumas-Gaudot, E.; Rubiales, D.; Jorrin, J.V. 2004. A proteomic approach to studying plant response to crenate broomrape (Orobanche crenata) in pea (Pisum sativum). Phytochemistry, v.65, n.12, p.1817-1828.

Chinnasamy, G.; Rampitsch, C. 2006. Efficient solublization buffers for two-dimensional gel electrophoresis of acidic and basic proteins extracted from wheat seeds. Biochimica et Biophysica Acta, v.1764, n.4, p.641-644.

Colditz, F.; Nyamsuren, O.; Niehaus, K.; Eubel, H.; Braun, H.P.; Krajinski, F. 2004. Proteomic approach: identification of Medicago truncatula proteins induced in roots after infection with the pathogenic oomycete Aphanomyces euteiches. Plant Molecular Biology, v.55, n.1, p.109-120.

Dangl, J.F.; Jones, J.D.G. 2001. Plant pathogens and integrated defence responses to infection. Nature, v.411, p.826-833.

De Mot, R.; Vanderleyden, J. 1989. Application of two-dimensional protein analysis for strain fingerprinting and mutant analysis of Azospirillum species. Canadian Journal of Microbiology, v.35, p.960-967.
Desimone, M.; Henke, A.; Wagner, E. 1996. Oxidative stress induces partial degradation of the large subunit of ribulose 1,5biphosphate carboxylase/oxygenase in isolated chloroplasts of barley. Plant Physiology, v.111, p.789-796.

Duarte, M.L.R.; Albuquerque, F.C.; Chu, E.Y.; Benchimol, R.L.; Poltronieri, L.S. Manejo integrado da fusariose e da murcha amarela da pimenteira-do-reino. 2002. In: POLTRONIERI, L.S.; TRINDADE, D.R. (Ed.). Manejo integrado das principais doenças de cultivos amazônicos. Belém: Embrapa Amazônia Oriental, p1-16.

Galau, G. A.; Wang, H. Y. C.; Wayne H. D. 1991. Sequence of the Gossypium hirsutum D-Genome Alloallele of Legumin A and its mRNA. Plant Physiology, v.3, p.1268-1270.

Kim, S.T.; Cho, K.S.; YU, S.; Kim, S.G.; Hong, J.C.; Han, C.D.; Bae, D.W.; Nam, M.H.; Kang, K.Y. 2003. Proteomic analysis of differentially expressed proteins induced by rice blast fungus and elicitor in suspension-cultured rice cells. Proteomics, v.3, n.12, p.2368-2378.

Kumar, D.; Klessig, D.F. 2000. Differential induction of tobacco MAP kinases by the defense signals nitric oxid, salicylic, acid, ethylene, and jasmonic acid. Molecular Plant Microbe Interaction, v.13, n.3, p.347-351.

Laemmli, U.K. 1970. Cleavage of structural proteins during the assembly of the head of bacteriophage T4. Nature, v.227, p.680-685.

Medeiros, R.B.; Ferreira, M.A.S.V.; Dianese, J.C. 2003. Mecanismos de agressão e defesa nas interaçóes planta-patógeno. Brasília: Universidade de Brasília, 209p.

Morgano, M. A.;Faria, C. G.; Ferrao, M. F. 2005. Determination of protein in raw coffee for NIR spectroscopy and regression PLS. Ciência Tecnologia de Alimentos, v.25, p.25-31.

Nürnberger, T. 1999. Signal perception in plant pathogen defense. Cellular and Molecular Life Science, v.55, p.167-182.

Oakley, B.R., Kirsch, D.R., Morris, N.R. 1980. A simplified ultrasensitive silver stain for detecting proteins in polyacrylamide gels. Analytical Biochemistry, v.105, n.2, p.361-3.

Osbourn, A. 1996. Preformed antimicrobial compounds and plant defense against fungal attack. The Plant Cell, v.8, p.18211831.

Park, K.O. 2004. Proteomic studies in plants. Journal of Biochemistry and Molecular Biology, v.37, p.133-138.

Patton, W.F. 2002. Detection technologies in proteome analysis. Journal of Chromatography B, v.771, p.3-31.

Peck, S.C.; Nuhse, T.S.; Hess, D.; Iglesias, A.; Meins, F.; Boller, T. 2001. Directed proteomics identifies a plant-specific protein rapidly phosphorylated in response to bacterial and fungal elicitors. The Plant Cell, v.13, p.1467-1475.

Peng-Da MA, Tian-Cheng LU, Xiao-Fu ZHOU, Xiao-Juan ZHU, and Xing-Zhi WANG 2004. Preparation of Polyclonal Antibodies of Rubisco Large and Small Subunits and Their Application in the Functional Analysis of the Genes. Acta Biochimica et Biophysica Sinica, v.36, n.9, p.644-648

Poltronieri, M.C.; Lemos, O.F.; Albuquerque, F.C. 1999. Pimentado-reino (Piper nigrum L.). In: Embrapa Amazônia Oriental 
(Ed). Programa de melhoramento genético e de adaptação de espécies vegetais da Amazônia Oriental. Belém: Embrapa Amazônia Oriental. Documentos, v.16, p. 127-137.

Sharma, N.; Rahman, M.H.; Strelkov, S.; Thiagarajah, M.; Bansal, V.K.; Kav, N.N.V. 2007. Proteome-level changes in two Brassica napus lines exhibiting differential responses to the fungal pathogen Alternaria brassicae. Plant Science, v.172, p.95-110.

Vâlcu, C.M.; Schlink, K. 2006. Efficient extraction of proteins from woody plant samples for two-dimensional electrophoresis. Proteomics, v.6, n.14, p.4166-75.

Wang, D.; Eyles, A.; Mandich, D.; Bonello, P. 2006. Systemic aspects of host-pathogen interactions in Austrian pine (Pinus nigra): A proteomics approach. Physiological and Molecular Plant Pathology, v. 68, n. $4-6$, p. $149-157$.
Weiss, W.; Görg, A. 2008. Sample solublization buffers for twodimensional electrophoresis. Methods in Molecular Biology, v.424, p.35-42.

Xie ,H.; Pan, S.; Liu ,S.; Ye K.; Huo,K. 2007. A novel method of protein extraction from perennial Bupleurum root for 2-DE. Electrophoresis, v. 28, p. $871-875$

Yamamoto, E. and Knap, H. T. 2001. Soybean Receptor-like Protein Kinase Genes:

Recebido em 28/11/2007

Aceito em 18/03/2009 